\title{
Observational Study of the Downstream Consequences of Inappropriate MRI of the Lumbar Spine
}

\author{
Josephine C. Jacobs, $P h D^{7,2}$ (D), Jeffrey G. Jarvik, MD, MPH ${ }^{3}$, Roger Chou, $M D^{4,5}$, \\ Derek Boothroyd, $\mathrm{PhD}^{6}$, Jeanie Lo, $\mathrm{MPH}^{7}$, Andrea Nevedal, PhD'², and Paul G. Barnett, \\ $P h D^{1,2}$
}

\begin{abstract}
'Health Economics Resource Center (HERC), VA Palo Alto Health Care System, Menlo Park, CA, USA; ${ }^{2}$ Center for Innovation to Implementation, VA Palo Alto Health Care System, Menlo Park, CA, USA; ${ }^{3}$ Departments of Radiology, Neurological Surgery and Health Services, University of Washington, Seattle, WA, USA; ${ }^{4}$ Department of Clinical Epidemiology and Medical Informatics, Oregon Health \& Science University, Portland, OR, USA; ${ }^{5}$ Department of Medicine, Oregon Health \& Science University, Portland, OR, USA; ' ${ }^{2}$ uantitative Research Unit, Stanford University Medical School, Stanford, CA, USA.
\end{abstract}

BACKGROUND: Contrary to guidelines, magnetic resonance imaging (MRI) is often ordered in the first 6 weeks of new episodes of uncomplicated non-specific low back pain.

OBJECTIVE: To determine the downstream consequences of early imaging.

DESIGN: Retrospective matched cohort study using data from electronic health records of primary care clinics of the U.S. Department of Veterans Affairs.

PARTICIPANTS: Patients seeking primary care for nonspecific low back pain without a red flag condition or an encounter for low back pain in the prior 6 months $(N=$ 405,965).

EXPOSURE: MRI of the lumbar spine within 6 weeks of the initial primary care visit.

MAIN MEASURES: Covariates included patient demographics, health history in the prior year, and baseline pain. Outcomes were lumbar surgery, prescription opioid use, acute health care costs, and last pain score recorded within 1 year of the index visit.

KEYRESULTS: Early MRI was associated with more back surgery ( $1.48 \%$ vs. $0.12 \%$ in episodes without early MRI), greater use of prescription opioids (35.1\% vs. $28.6 \%$ ), a higher final pain score (3.99 vs. 3.87), and greater acute care costs (\$8082 vs. \$5560), $p<0.001$ for all comparisons.

LIMITATIONS: Reliance on data gathered in normal clinical care and the potential for residual confounding despite the use of coarsened exact matching weights to adjust for baseline differences.

CONCLUSIONS: The association between early imaging and increased utilization was apparent even in a setting largely unaffected by incentives of fee-for-service care. Reduced imaging cost is only part of the motivation to improve adherence with guidelines for the use of MRI. Early scans are associated with excess surgery, higher costs for other care, and worse outcomes, including potential harms from prescription opioids.

Electronic supplementary material The online version of this article (https://doi.org/10.1007/s11606-020-06181-7) contains supplementary material, which is available to authorized users.

Received March 11, 2020

Accepted August 24, 2020

Published online September 28, 2020
KEY WORDS: inappropriate magnetic resonance imaging; low back pain; retrospective matched cohort study; downstream consequences; primary care providers.

$\mathrm{J}$ Gen Intern Med 35(12):3605-12 DOI: $10.1007 / \mathrm{s} 11606-020-06181-7$

(C) Society of General Internal Medicine (This is a U.S. government work and not under copyright protection in the U.S.; foreign copyright protection may apply) 2020

\section{INTRODUCTION}

Low back pain is the second most common symptomatic reason for physician office visits, ${ }^{1}$ and the associated health care costs are rapidly rising. ${ }^{2}$ One reason for this increase is the inappropriate use of advanced imaging, particularly magnetic resonance imaging (MRI), for uncomplicated non-specific low back pain. ${ }^{3}$ Routine use of MRIs in low back pain cases is common, with 16 to $21 \%$ of low back pain patients in commercial health care plans and $12 \%$ of Medicare patients receiving an MRI. ${ }^{4}{ }^{5}$ Clinical guidelines recommend that new episodes of non-specific low back pain not complicated by red flag conditions should be treated with conservative therapy and that MRI is not indicated in the first 6 weeks of onset. ${ }^{6}$ However, studies have found that 26 to $44 \%$ of spine MRIs are not guideline-concordant. ${ }^{7-10}$

There is growing evidence that the consequences of inappropriate imaging for uncomplicated non-specific low back pain extend beyond the direct costs of an MRI. Potential downstream consequences include subsequent referrals and interventions performed as a result of imaging. Rates of lumbar spine procedures, including surgery, epidural steroid injections, and facet joint injections, are also increasing and are part of the higher costs associated with inappropriate imaging. ${ }^{11-13}$ There is no evidence that these additional procedures lead to better outcomes, and they may even result in more harm than benefit. ${ }^{11,12,14,15}$ The downstream effects of early MRI of the lumbar spine on costs, procedures, and opioid use remain underexplored in the literature, while the effects on pain outcomes have yet to be studied. This study fills these gaps, exploring the association between early MRI and surgery, opioid use, cost, and the course of patient pain. 


\section{METHODS}

We conducted a retrospective matched cohort study of new episodes of uncomplicated non-specific low back pain. We used data from the U.S. Department of Veterans Affairs (VA) Corporate Data Warehouse, a national repository of extracts of electronic health records. A summary of the databases used can be found in Appendix 1. The study protocol was approved by the Administrative Panels for the Protection of Human Subjects of Stanford University.

\section{Cohort}

Individuals were eligible for inclusion if they had a visit for uncomplicated low back pain in a VA primary care clinic between June 1, 2015, and June 30, 2016. Uncomplicated low back pain visits were characterized with a diagnosis of non-specific pain of the lower back: lumbar sprain, strain, spondylosis, or disk degeneration. Visits characterized exclusively by diagnosis codes for generalized back pain were excluded: unspecified backache (ICD-9 code 724.5), other dorsalgia, or unspecified dorsalgia (ICD-10 codes M5489 and M549). Visits were excluded if they were also characterized with a specific diagnosis of myelopathy, radiculopathy, sciatica, injury to the coccyx, spinal stenosis, or disk herniation.

Visits were excluded if there was a "red flag" condition, as defined by the Medicare performance measure for appropriateness of lumbar spine MRI (LS-MRI), ${ }^{16}$ present in VA hospital and outpatient data. These conditions included trauma in the prior 45 days; lumbar spine surgery in the past 90 days; cancer, neurologic impairment, infections, or injection drug use in the past year; or autoimmune, inflammatory, conditions, neoplastic abnormalities, radiation therapy, or congenital malformation in the last 5 years (i.e., a lookback period beginning June 1, 2010).

We considered a visit the start of a new episode if there was no VA-provided or VA-sponsored care in the prior 6 months with a diagnosis involving pain to the thoracic, lumbar, sacral, or sacrococcygeal spine. When patients had more than one episode in the study year, the first episode was selected for study. Less than $5 \%$ of patients had multiple episodes in the study year.

\section{Early MRI Scan}

Scans were identified using Current Procedure Terminology codes for LS-MRI (72148, 72158). Scans provided within 6 weeks of the index visit were deemed "early," which is consistent with guidelines for treatment of low back pain. ${ }^{6}$

\section{Matching Approach}

Patients with early MRI were matched to patients without an early MRI using coarsened exact matching (CEM). CEM assigns individuals from each group to strata within which individuals share the same coarsened values. ${ }^{17-19}$ Individuals exposed to an early MRI were assigned a value of 1 . Unexposed individuals were assigned a weight that accounts for the number of exposed and unexposed observations within that strata and the total number of exposed and unexposed observations that were matched. The matching was based on patient baseline characteristics: demographics (age and sex); index visit pain score, having an assigned primary care provider; residing $\geq 40$ miles from the nearest VA facility; and a history of a pain condition, a mental health condition, or a prescription for opioids in the previous 12 months.

\section{Outcome Measures}

Time Horizon. Outcomes were measured from 43 to 365 days post-index visit, and costs were also measured for the first 42 days. We excluded the 42-day post-index visit, as this was the time period used to assess whether an individual received an early MRI scan.

Probability of Lumbar Surgery. Lumbar-related spinal surgeries included surgical procedures conducted on the lumbar, lumbosacral, and thoracolumbar regions in an inpatient or outpatient setting. Surgeries provided in the hospital were identified with ICD-9 or ICD-10 procedure codes. Surgeries provided in outpatient settings were identified using CPT codes when the encounter included a diagnosis code for low back pain.

Opioid Use. Opioid prescriptions were defined as long-acting opioids, short-acting opioids, and tramadol, with doses converted to morphine equivalents using Centers for Disease Control conversion factors. ${ }^{20}$

Pain Score. During most encounters, VA patients are asked to report their pain on a scale from 0 to 10 . We used the first value recorded on any given date. Values were found for $95.0 \%$ of index visits. Follow-up scores recorded 43-365 days after the index visit were found for $77.4 \%$ of episodes. We used the last score reported in this period. The mean time to this follow-up was 272 days after the index visit.

Cost. Cost was tallied for the 6-week period of exposure to early MRI as well as the follow-up period from weeks 7 to 52 . Sub-totals were calculated for back-related care and care unrelated to the back. Sub-totals were also calculated for outpatient and inpatient care. Costs included both VA-provided care and care purchased by VA. The costs of long-term care and homeless domiciliary services were excluded. Hospital stays were considered back-related if the primary diagnosis was for low back pain; outpatient visits were considered back-related if any of the assigned diagnoses was back-related (no diagnosis is considered primary in outpatient records). 


\section{Statistical Analyses}

Baseline characteristics of patients with early MRI were compared with those of patients without early MRI by calculating the standardized difference of the means using pooled variance. Both a raw standardized difference and a CEM-weighted standardized difference were compared.

The association between early MRI and each outcome was determined by multivariable regressions adjusted with CEM weights and controlling for baseline covariates: demographics (age and sex); primary care provider characteristics (whether the patient was assigned to a provider, whether the assigned provider was seen on the index visit, provider's panel size, and type of clinic visited at the index visit); case-mix (pain score at the index visit, history of opioid use in the prior year, time between the index visit and the last low back pain visit, total VA costs in the prior year, and total morphine equivalents in the prior year); and indicators for chronic conditions, mental health diagnoses, and pain conditions.

Logistic regression was estimated for the lumbar surgery and prescription opioid outcomes. The adjusted absolute proportion of each outcome was found as the mean of the predicted values of the logistic regression. Log-binomial and Poisson regressions were used to estimate relative risks. ${ }^{21}$ Generalized linear model (GLM) regressions were specified for continuous variables. Box-Cox regression was used to identify the link function and a modified Park test was used to identify the appropriate distribution. ${ }^{22}$ GLM with a log link and gamma distribution accommodates the skewed distribution and heteroscedastic errors of costs. ${ }^{23,} 24$ These specifications were used for all cost outcomes except acute cost in the first 42 days of the episode, for the appropriate distributional assumption was inverse normal. Absolute difference in means between those with an early scan and the comparison group was estimated as the difference in the mean antilog of the fitted values, with standard errors estimated using the delta method. ${ }^{25}$ The ratio of costs of the early MRI group relative to the comparison group was estimated by adding one to the regression parameter for the indicator of early exposure to MRI. The parameter for an indicator variable in a log model represents the proportional change, so adding one to this value is the ratio of the fitted value of observations with the indicator (those with early MRI) to the fitted value of observations without the indicator.

Two-part models were used to accommodate the large number of zero values for the last recorded pain score and quantity of opioid use outcomes. ${ }^{26}$ Logistic regression modeled the probability of a non-zero value, while GLM regressions were used for the second part. An identity link and inverse normal distribution were specified for the last recorded pain score. A log link and Poisson distribution were specified for the quantity of opioids. We estimated the distribution of the standard errors using 1000 bootstrap replicates. ${ }^{26}$ Analyses were conducted using Stata version 15. ${ }^{27}$

\section{RESULTS}

There were 1.17 million VA primary care visits for nonspecific low back pain in the year ending June 30, 2016 (Fig. 1). Applying our exclusion criteria resulted in a cohort of 442,284 observations. Another 22,465 persons were excluded because of missing pain and clinic information from their index visit. An additional 14,133 persons were excluded because they could not be matched using CEM. Almost all (99.9\%) unmatched observations were episodes without an early scan. This left 405,965 observations for study, or $91.7 \%$ of the 442,284 episodes of uncomplicated nonspecific low back pain.

There were 9977 individuals (2.46\%) who received a LSMRI within 6 weeks of their index visit. Table 1 compares patients with non-specific low back pain who received an early scan with those who did not and summarizes the standardized difference in the means for each variable of interest with and without CEM weights. Patients with an early scan were younger, were less likely to have an assigned primary care provider, were less likely to have seen their assigned primary care provider, had higher baseline pain, were less likely to have had a back pain episode in the previous 24 months, had fewer chronic conditions, and were less likely to have a diagnosis of hypertension or ischemic heart disease in the prior year. After CEM adjustment, all standardized differences had an absolute value of less than $10 \%$, a frequently used criterion for adequacy of propensity adjustment. ${ }^{21}$

Table 2 summarizes unadjusted means and proportions of the outcome variables during the follow-up period. Compared with patients who did not receive an early scan, patients with an early MRI had more lumbar surgery (1.49\% vs. $0.09 \%)$, were more likely to receive a prescription for opioids (36.7\% vs. $28.5 \%$ ), and had a higher pain score at follow-up (3.87 vs. $3.28)(p<0.001)$. The unadjusted analysis found no difference in the mean quantity of prescription opioids used (1.61 thousand $\mathrm{mg}$ of morphine equivalents (MME) for those with an early scan vs. 1.60 for those without one, $p=0.51$ ). Patients with an early MRI had greater costs for acute care during the initial exposure period (\$2254 vs. \$1100) and in the follow-up period (\$7501 vs \$5112). The costs of care related to back pain, care not related to back pain, inpatient services, and outpatient services were greater in the group that had an early scan. These differences were statistically significant $(p<$ $0.001)$.

Table 3 presents CEM-weighted analyses with adjustment for baseline covariates. CEM weighting and covariate adjustment resulted in a small attenuation of the estimated association between early scans and outcomes. Using the adjusted log-binomial model, receipt of an early scan was associated with a higher risk of lumbar surgery (adjusted relative risk 12.7 [95\% CI 10.3-15.5]). The adjusted absolute percentages were $1.48 \%$ among episodes with an early MRI vs. $0.12 \%$ for those without an early MRI. In the adjusted Poisson model, early MRI was also associated with a greater likelihood of 


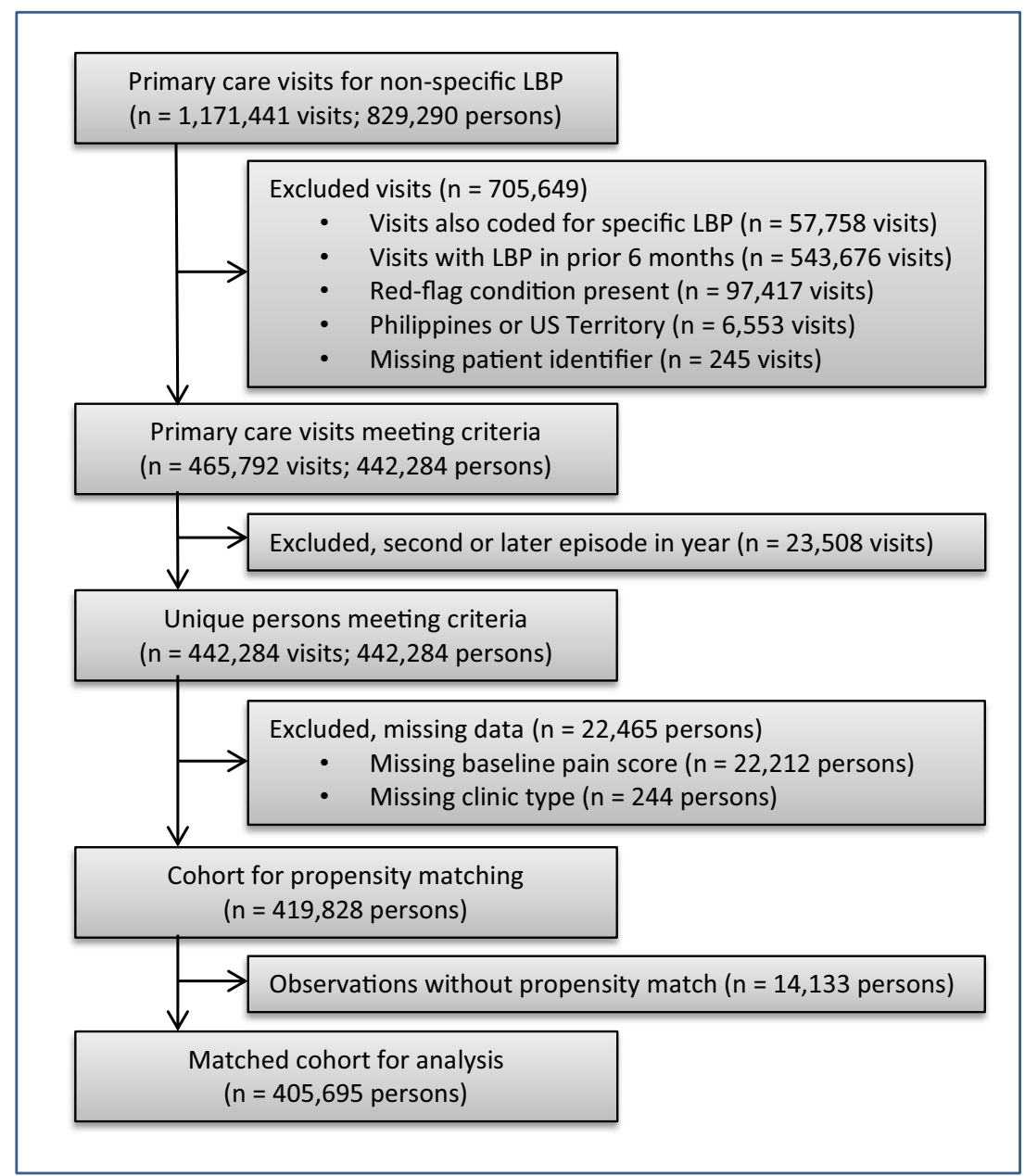

Figure 1 Effect of exclusion criteria on the size of study cohort.

receiving a prescription for opioids (adjusted relative risk 1.23 [95\% CI 1.20-1.27]). Among those receiving an early MRI, the adjusted absolute percentage receiving prescription opioids in the follow-up period was $35.1 \%$, compared with $28.6 \%$ in the comparison group. Results of the adjusted two-part models indicated that in the follow-up period, early MRI recipients received a greater mean quantity of prescription opioids (1.9 thousand MME (i.e., 5.9 MME/day) vs. 1.81 thousand (i.e., 5.6 MME/day) in the comparison group ( $p=$ $0.03)$ ) and had a higher pain score (3.99 vs. 3.87 in the comparison group $(p<0.001))$.

The adjusted GLM regressions indicated that early scans were associated with higher costs in the followup period. The adjusted mean acute care cost of patients receiving an early MRI was $\$ 8082$ compared with $\$ 5560$ in patients not receiving an early MRI $(p<$ $0.001)$, an absolute difference of $\$ 2522$ (95\% CI 2202-2841). This difference represented $\$ 1347$ greater cost for back pain care (95\% CI 1198-1497) and $\$ 1155$ greater cost for other health services (95\% CI 9031407). The difference can also be represented as $\$ 938$ greater cost of inpatient care (95\% CI 649-1228) and $\$ 1635$ additional cost for outpatient care (95\% CI $1477-$
1793). The early MRI group incurred $\$ 1219$ greater costs during the first 42 days of the episode, when the MRI was provided (95\% CI 1125-1313).

\section{DISCUSSION}

This study found that an MRI of the lumbar spine provided early in episodes of non-specific low back pain was associated with more surgery, greater costs of care, greater prescription opioid use, and worse pain at follow-up. Lumbar surgery was 13 times more likely in the group with early MRI compared with that in those without an early scan (1.48\% vs. $0.09 \%)$. This is consistent with other observational studies, where surgery was 5 to 20 times more likely among those receiving an early MRI. ${ }^{3}, 12,28$ Absolute rates of surgery in this study were much lower than in these other studies, however. In those studies, lumbar surgery was provided in $14-22 \%$ of those with an early scan and in 1-3\% without an early scan. These studies had approximately 10 times that rate of lumbar surgery that we observed in VA.

Despite additional surgeries and higher rates and doses of opioid prescriptions, recipients of early scans had worse pain at follow-up relative to the comparison group. This result was 
Table 1 Baseline Characteristics of Veterans with Non-specific Low Back Pain, by Groups Defined by Subsequent Exposure to Early Lumbar MRI

\begin{tabular}{|c|c|c|c|c|}
\hline \multirow[t]{2}{*}{ Patient characteristic } & \multirow[t]{2}{*}{ With early MRI $(N=9,977)$} & \multirow[t]{2}{*}{ Without early MRI $(N=395,718)$} & \multicolumn{2}{|c|}{ Standardized difference in means } \\
\hline & & & Unweighted & After CEM adjustment \\
\hline Patient age (mean, in years) & 52.2 & 56.5 & -0.277 & -0.057 \\
\hline$<40$ years $(\%)$ & 24.9 & 18.4 & 0.159 & 0.000 \\
\hline $40-50$ years $(\%)$ & 19.0 & 15.3 & 0.098 & 0.088 \\
\hline $51-60$ years $(\%)$ & 21.2 & 20.4 & 0.019 & -0.014 \\
\hline $61-70$ years $(\%)$ & 25.7 & 29.4 & -0.084 & -0.062 \\
\hline $71+$ years $(\%)$ & 9.2 & 16.4 & -0.218 & 0.000 \\
\hline Female gender $(\%)$ & 7.1 & 5.5 & 0.066 & 0.000 \\
\hline Travel distance to nearest VA clinic (miles) & 16.5 & 16.2 & 0.018 & 0.042 \\
\hline Travel distance to nearest VA tertiary hospital (miles) & 101.5 & 99.3 & 0.023 & 0.040 \\
\hline Travel distance to nearest VA tertiary hospital $>40$ miles $(\%)$ & 70.5 & 71.6 & -0.025 & 0.003 \\
\hline Patient had an assigned primary care provider $(\%)$ & 90.3 & 93.3 & -0.110 & 0.000 \\
\hline Patient saw assigned primary care provider $(\%)$ & 80.2 & 84.8 & -0.120 & -0.017 \\
\hline Index visit at satellite clinic & 52.5 & 58.7 & -0.125 & -0.102 \\
\hline \multicolumn{5}{|l|}{ Baseline pain score (numeric) } \\
\hline Baseline pain score $0(\%)$ & 12.7 & 31.8 & -0.472 & 0.000 \\
\hline Baseline pain score $1(\%)$ & 1.8 & 2.4 & -0.041 & 0.000 \\
\hline Baseline pain score $2(\%)$ & 3.6 & 4.5 & -0.046 & 0.000 \\
\hline Baseline pain score $3(\%)$ & 8.5 & 8.5 & 0.000 & 0.000 \\
\hline Baseline pain score $4(\%)$ & 9.8 & 8.8 & 0.035 & 0.000 \\
\hline Baseline pain score $5(\%)$ & 12.3 & 10.8 & 0.049 & 0.000 \\
\hline Baseline pain score $6(\%)$ & 12.8 & 9.9 & 0.091 & 0.000 \\
\hline Baseline pain score $7(\%)$ & 13.7 & 9.8 & 0.121 & 0.000 \\
\hline Baseline pain score $8(\%)$ & 13.9 & 8.6 & 0.167 & 0.000 \\
\hline Baseline pain score $9(\%)$ & 5.6 & 2.7 & 0.142 & 0.000 \\
\hline Baseline pain score $10(\%)$ & 5.4 & 2.3 & 0.165 & 0.000 \\
\hline Back pain visit in prior 6-12 months $(\%)$ & 37.6 & 39.4 & -0.037 & -0.036 \\
\hline Back pain visit in prior $12-24$ months (\%) & 23.4 & 26.7 & -0.076 & -0.058 \\
\hline No visit for back pain in last 24 months (\%) & 39.0 & 33.9 & 0.106 & 0.088 \\
\hline Total cost in the year prior to the index visit (mean \$US) & 4482 & 3802 & 0.084 & 0.064 \\
\hline History of any opioid prescription in prior year $(\%)$ & 19.7 & 20.0 & -0.006 & -0.047 \\
\hline Received $1-900 \mathrm{mg}$ of opioids in prior year $(\%)$ & 8.1 & 7.0 & 0.044 & 0.020 \\
\hline Received $901-3600 \mathrm{mg}$ of opioids in prior year (\%) & 5.9 & 6.5 & -0.025 & -0.038 \\
\hline Received $>3600 \mathrm{mg}$ of opioids in prior year $(\%)$ & 5.7 & 6.5 & -0.033 & -0.062 \\
\hline Number of chronic health conditions in prior year (mean) & 1.51 & 1.73 & -0.153 & -0.082 \\
\hline Acid-related diseases $(\%)$ & 10.0 & 13.0 & -0.095 & -0.067 \\
\hline Arthritis (\%) & 6.9 & 7.2 & -0.014 & -0.014 \\
\hline Asthma $(\%)$ & 3.7 & 4.1 & -0.018 & -0.028 \\
\hline Congestive heart failure $(\%)$ & 1.5 & 2.4 & -0.071 & -0.049 \\
\hline Chronic obstructive pulmonary disease $(\%)$ & 10.4 & 11.9 & -0.048 & -0.028 \\
\hline Diabetes $(\%)$ & 18.0 & 20.9 & -0.074 & -0.041 \\
\hline Headache $(\%)$ & 10.7 & 9.5 & 0.042 & -0.012 \\
\hline Hepatitis C (\%) & 2.2 & 2.4 & -0.014 & -0.028 \\
\hline Hypertension (\%) & 43.2 & 49.6 & -0.129 & -0.049 \\
\hline Ischemic heart disease $(\%)$ & 8.1 & 11.4 & -0.110 & -0.038 \\
\hline Prostatic hyperplasia (\%) & 8.0 & 10.9 & -0.098 & -0.019 \\
\hline Peripheral vascular disease $(\%)$ & 3.2 & 3.6 & -0.026 & 0.007 \\
\hline Renal failure $(\%)$ & 2.9 & 4.3 & -0.071 & -0.032 \\
\hline Stroke $(\%)$ & 2.5 & 3.0 & -0.031 & -0.001 \\
\hline Mental health diagnosis in prior year $(\%)$ & 42.2 & 39.0 & 0.067 & -0.005 \\
\hline Alcohol abuse $(\%)$ & 4.3 & 4.1 & 0.013 & -0.005 \\
\hline Alcohol dependence $(\%)$ & 3.3 & 3.2 & 0.007 & -0.006 \\
\hline Drug dependence or abuse (\%) & 3.7 & 3.5 & 0.013 & -0.022 \\
\hline Bipolar disorder $(\%)$ & 27.1 & 24.8 & 0.052 & -0.002 \\
\hline Depression $(\%)$ & 2.7 & 2.4 & 0.019 & 0.001 \\
\hline Post-traumatic stress disorder $(\%)$ & 23.3 & 20.0 & 0.080 & 0.017 \\
\hline Schizophrenia $(\%)$ & 0.8 & 1.1 & -0.036 & -0.039 \\
\hline Diagnosis of painful condition in prior year $(\%)$ & 66.5 & 63.4 & 0.066 & 0.000 \\
\hline Abdominal pain $(\%)$ & 4.8 & 3.8 & 0.047 & 0.028 \\
\hline Arthropathy $(\%)$ & 11.9 & 12.8 & -0.025 & -0.020 \\
\hline Back and neck pain (\%) & 8.6 & 6.6 & 0.077 & 0.050 \\
\hline Fibromyalgia $(\%)$ & 1.9 & 1.4 & 0.033 & 0.011 \\
\hline Headache or migraine & 10.7 & 9.5 & 0.041 & -0.012 \\
\hline Joint pain $(\%)$ & 34.7 & 30.4 & 0.091 & 0.016 \\
\hline Limb pain $(\%)$ & 9.9 & 8.2 & 0.059 & 0.031 \\
\hline Neuropathy (\%) & 16.9 & 14.2 & 0.074 & 0.050 \\
\hline Osteopathy $(\%)$ & 20.8 & 20.6 & 0.003 & 0.007 \\
\hline Central pain syndrome or chronic pain $(\%)$ & 8.1 & 7.7 & 0.013 & -0.009 \\
\hline
\end{tabular}

consistent with studies that have found no health benefit from early MRI. ${ }^{29,30}$ This study found that acute care costs incurred in the follow-up period were 1.4 times greater in the early scan group (\$8082 vs. \$5560). This was smaller than in other 
Table 2 Unadjusted Means of Outcomes and Cost in Veterans with Non-specific Low Back Pain, by Exposure to Early Lumber MRI

\begin{tabular}{llll}
\hline \hline Outcome & With early MRI $(\boldsymbol{N = 9 9 7 7 )}$ & Without early MRI $(\boldsymbol{N = 3 9 5 , 7 1 8 )}$ & $\boldsymbol{p}$ \\
\hline Lumbar surgery (\%) & 1.49 & 0.09 & $<0.001$ \\
Prescription opioid use (\%) & 36.7 & 28.5 & $<0.001$ \\
Quantity of prescription opioids, 1000 mg of morphine & $1.61[5.96]$ & $1.60[6.03]$ & 0.51 \\
equivalents (mean [standard deviation]) & $3.87[3.12]$ & $3.28[3.18]$ & $<0.001$ \\
Last recorded pain score (mean [standard deviation]) & & $1100[3089]$ & $<17[4516]$ \\
Costs 2016 \$US (mean [standard deviation]) & $2254[5348]$ & $4496[11,887]$ & $<0.001$ \\
Acute care costs, 0-42 days after index visit & $1825[1825]$ & $1204[9451]$ & $<0.001$ \\
Acute care costs, 43-365 days after index visit & $5676[12,382]$ & $3909[7741]$ & $<0.001$ \\
$\quad$ Care related to back pain & $1920[11,211]$ & $5112[13,357]$ & $<0.001$ \\
Care not related to back pain & $5581[7600]$ & $<0.001$ \\
$\quad$ Inpatient care & $7501[15,029]$ & $<0.001$ \\
Outpatient care & &
\end{tabular}

studies, where the MRI group had 3-8 times the cost of the comparison group. $3,12,27$

The finding that early MRI was associated with greater use of opioids over the follow-up period appears to be a unique contribution of this study-one that is especially important given concerns over hazards resulting from over-prescription of opioids for pain. We found only one clinical trial that considered this outcome, and it found no significant association between early MRI and prescription opioid use. ${ }^{29}$ Other studies did not consider this outcome. ${ }^{3}, 12,28,31$

Early MRI was provided to $2.46 \%$ of this cohort. This is a lower rate than in other studies where the denominator was MRI scans as opposed to primary care visits for low back pain. It may also be lower than expected because VA providers are salaried and not affected by financial incentives present in feefor-service settings. Self-referral drives some of the high use of LS-MRI in patients sponsored by Medicare, ${ }^{32}$ although Federal statutes on self-referral may have reduced this practice. In addition, it is possible that VA providers are less likely to practice "defensive medicine," as malpractice liability in the VA system is the responsibility of the Federal government.

This study used electronic health records to assemble the largest cohort used to estimate the downstream consequences of early MRI. The size of this cohort $(N=$ $405,965)$ was more than 10 times the size of other observational studies ${ }^{3,12,28}$ and more than 400 times the size of clinical trials that addressed this issue. ${ }^{29,} 31$ While large cohort studies have the advantage of gathering evidence from generalized, real-world experience, they must address the problem of selection bias: patients were not randomized to receive an early scan. Older methods, including simple covariate adjustment ${ }^{33}$ and inclusion of a propensity score as covariate, ${ }^{28}$ have now been replaced by more advanced methods of matching. ${ }^{3,18,19}$ This study used CEM while also controlling for covariates, including prior year health expenditures, prior year use of prescription opioids, history of medical and psychiatric conditions, and use of back pain services.

Table 3 Propensity and Covariate Adjusted Means and Marginal Effects of Study Outcomes in Veterans with Non-specific Low Back Pain

\begin{tabular}{|c|c|c|c|c|c|}
\hline \multirow[t]{2}{*}{ Outcome } & \multicolumn{2}{|c|}{ Adjusted mean } & \multirow[t]{2}{*}{$p$} & \multirow{2}{*}{$\begin{array}{l}\text { Absolute difference } \\
\text { [95\% CI] }\end{array}$} & \multirow{2}{*}{$\begin{array}{l}\text { Relative risk/ratio of ad- } \\
\text { justed means* }[95 \% \mathrm{CI}]\end{array}$} \\
\hline & $\begin{array}{l}\text { With early } \\
\text { MRI }(N= \\
\text { 9977) }\end{array}$ & $\begin{array}{l}\text { Without early MRI } \\
(N=395,718)\end{array}$ & & & \\
\hline Lumbar surgery $(\%)$ & 1.48 & 0.12 & $<0.001$ & $1.36[1.12-1.60]$ & $12.7[10.3-15.5]$ \\
\hline Prescription opioid use (\%) & 35.1 & 28.6 & $<0.001$ & $6.8[6.0-7.8]$ & $1.23[1.20-1.27]$ \\
\hline $\begin{array}{l}\text { Quantity of prescription opioid, } \\
1000 \mathrm{mg} \text { of morphine equivalents } \\
\text { (mean) }\end{array}$ & 1.90 & 1.81 & 0.03 & $0.13[0.01-0.24]$ & $1.06[1.00-1.13]$ \\
\hline Last recorded pain score (mean) & 3.99 & 3.87 & $<0.001$ & $0.15[0.09-0.22]$ & $1.04[1.02-1.06]$ \\
\hline Costs 2016 \$US (mean) & & & & & \\
\hline $\begin{array}{l}\text { Acute costs, 0-42 days } \\
\text { after index visit } \\
\text { Acute care costs, 43-365 } \\
\text { days after index visit }\end{array}$ & 2391 & 1171 & $<0.001$ & 1219 [1125-1313] & $1.71[1.67-1.75]$ \\
\hline Back pain care & 2054 & 706 & $<0.001$ & 1347 [1198-1497] & $2.07[1.99-2.14]$ \\
\hline Other than back pain care & 6018 & 4863 & $<0.001$ & $1155[903-1407]$ & $1.21[1.17-1.26]$ \\
\hline Inpatient care & 2371 & 1433 & $<0.001$ & $938[649-1228]$ & $1.50[1.38-1.63]$ \\
\hline Outpatient care & 5861 & 4226 & $<0.001$ & $1635[1477-1793]$ & $1.33[1.30-1.35]$ \\
\hline $\begin{array}{l}\text { Total acute care cost, } 43-365 \text { days } \\
\text { after index visit }\end{array}$ & 8082 & 5560 & $<0.001$ & $2522[2202-2841]$ & $1.37[1.33-1.41]$ \\
\hline
\end{tabular}

*Relative risks were calculated for binary outcomes and ratios of adjusted means for continuous variables 


\section{LIMITATIONS}

In using matching to address selection bias, we rely on the untestable assumption that observable characteristics explained the exposure of interest. As such, we cannot be certain that downstream surgeries, costs, pain levels, and opioid use directly resulted from early MRIs. Our measures of the potential benefit of early MRI were limited. Pain data were extracted from electronic health records completed during routine clinical care. Although just 5\% of the cohort were missing the pain score at baseline, $23 \%$ of the cohort did not have a pain score in the follow-up period. We assumed that missingness was not associated with outcomes, but as pain is correlated with care seeking, data are more likely to be missing in persons with less pain. The pain reported was not necessarily specific to the lumbar spine.

\section{CONCLUSION}

This study confirms that early LS-MRI is associated with increased surgery and higher costs. It expands upon prior studies by finding that early MRI is associated with worse pain and greater use of prescription opioids. An MRI provided early in episodes of uncomplicated non-specific low back pain not only is, therefore, an unnecessary expense, but also is associated with greater expenditures for other services, worse outcomes, and the potential harms of prescription opioids: their side effects, risk of abuse, and potential for overdose.

Corresponding Author: Josephine C. Jacobs, PhD; Health Economics Resource Center (HERC), VA Palo Alto Health Care System, Menlo Park, CA, USA (e-mail: josephine.jacobs@va.gov).

Funding The work was supported by VA Health Services Research \& Development Service Merit Review Award I01-HX002016.

\section{Compliance with Ethical Standards:}

The study protocol was approved by the Administrative Panels for the Protection of Human Subjects of Stanford University.

Conflict of Interest: The authors declare that they do not have a conflict of interest.

\section{REFERENCES}

1. Hart LG, Deyo RA, Cherkin DC. Physician office visits for low back pain. Frequency, clinical evaluation, and treatment patterns from a U.S. national survey. Spine. 1995;20(1):11-9.

2. Martin BI, Deyo RA, Mirza SK, Turner JA, Comstock BA, Hollingworth W, et al. Expenditures and health status among adults with back and neck problems. JAMA. 2008;299(6):656-64.

3. Fritz JM, Brennan GP, Hunter SJ. Physical therapy or advanced imaging as first management strategy following a new consultation for low back pain in primary care: associations with future health care utilization and charges. Health Serv Res. 2015;50(6):1927-40.

4. Dagenais S, Galloway EK, Roffey DM. A systematic review of diagnostic imaging use for low back pain in the United States. Spine J. 2014;14 (6): 1036-48.
5. Di Iorio D, Henley E, Doughty A. A survey of primary care physician practice patterns and adherence to acute low back problem guidelines. Arch Fam Med. 2000;9(10):1015-21.

6. Chou R, Gaseem A, Snow V, Casey D, Cross JT, Shekelle P, et al. Diagnosis and treatment of low back pain: a joint clinical practice guideline from the American College of Physicians and the American Pain Society. Ann Intern Med. 2007;147(7):478-91.

7. Lehnert BE, Bree RL. Analysis of appropriateness of outpatient CT and MRI referred from primary care clinics at an academic medical center: how critical is the need for improved decision support? J Am Coll Radiol. 2010;7(3): 192-7.

8. Picano E. Sustainability of medical imaging. BMJ. 2004;328(7439):57880.

9. Rao JK, Kroenke K, Mihaliak KA, Eckert GJ, Weinberger M. Can guidelines impact the ordering of magnetic resonance imaging studies by primary care providers for low back pain? Am J Manag Care. 2002;8 (1):27-35.

10. Emery DJ, Shojania KG, Forster AJ, Mojaverian N, Feasby TE. Overuse of magnetic resonance imaging. JAMA Intern Med. 2013;173 (9):823-5.

11. Lurie JD, Birkmeyer NJ, Weinstein JN. Rates of advanced spinal imaging and spine surgery. Spine. 2003;28(6):616-20.

12. Webster BS, Cifuentes M. Relationship of early magnetic resonance imaging for work-related acute low back pain with disability and medical utilization outcomes. J Occup Environ Med. 2010;52(9):900-7.

13. Ivanova JI, Birnbaum HG, Schiller M, Kantor E, Johnstone BM, Swindle RW. Real-world practice patterns, health-care utilization, and costs in patients with low back pain: the long road to guidelineconcordant care. Spine J. 2011;11(7):622-32.

14. Chou R, Fu R, Carrino JA, Deyo RA. Imaging strategies for low-back pain: systematic review and meta-analysis. Lancet. 2009;373(9662):46372.

15. Chou R, Deyo RA, Jarvik JG. Appropriate use of lumbar imaging for evaluation of low back pain. Radiol Clin N Am. 2012;50(4):569-85.

16. Yale-New Haven Health Services Corporation/Center for Outcomes Research and Evaluation (YNHHSC/CORE). MRI Lumbar Spine for Low Back Pain (OP-8) Comprehensive Reevaluation Report Deliverable \#21A. Report No.: Prepared for Centers for Medicare \& Medicaid Services (CMS) Contract Number: HHSM-500-2013-13018I, Task Order: HHSM-500T0002 Option Year One. 2016.

17. Blackwell M, Iacus S, King G, Porro G. cem: Coarsened exact matching in Stata. Stata J. 2009;9(4):524-46.

18. Iacus SM, King G, Porro G. Causal inference without balance checking: Coarsened exact matching. Political Anal. 2012; 20(1): 1-24.

19. King G, Nielsen R. Why propensity scores should not be used for matching. Political Anal. 2019; 27(4): 1-20.

20. Dowell D, Haegerich T, Chou R. CDC Guideline for Prescribing Opioids for Chronic Pain - United States, 2016. MMWR Recomm Rep [Internet]. 2016 [cited 2019 Sep 18];65. Available from: https://www.cdc.gov/ mmwr/volumes/65/rr/rr6501e1.htm.

21. Normand S, Landrum $\mathbf{M}$, Guadagnoli E. Validating recommendations for coronary angiography following acute myocardial infarction in the elderly: a matched analysis using propensity scores. J Clin Epidemiol. 2001;54(4):387-98.

22. Box GEP, Cox DR. An analysis of transformations. J R Stat Soc Se B (Methodological). 1964;26(2):211-43.

23. Manning WG, Basu A, Mullahy J. Generalized modeling approaches to risk adjustment of skewed outcomes data. J Health Econ. 2005;24 (3):465-88.

24. Manning WG, Mullahy J. Estimating log models: to transform or not to transform? J Health Econ. 2001;20(4):461-94.

25. Oehlert GW. A note on the Delta method. Am Stat. 1992;46(1):2.

26. Belotti F, Deb P, Manning W, Norton E. twopm: Two-part models. Stata Journal [Internet]. 2015 [cited 2019 Aug 12];15(1). Available from: https://econpapers.repec.org/article/agsstataj/271681.htm.

27. StataCorp. Stata Statistical Software: Release 15. College Station: StataCorp LLC; 2017.

28. Graves JM, Fulton-Kehoe D, Jarvik JG, Franklin GM. Health care utilization and costs associated with adherence to clinical practice guidelines for early magnetic resonance imaging among workers with acute occupational low back pain. Health Serv Res. 2014;49(2):645-65.

29. Jarvik JG, Hollingworth W, Martin B, Emerson SS, Gray DT, Overman $\mathbf{S}$, et al. Rapid magnetic resonance imaging vs radiographs for patients with low back pain: a randomized controlled trial. JAMA. 2003;289 (21):2810-8. 
30. Modic MT, Obuchowski NA, Ross JS, Brant-Zawadzki MN, Grooff PN, Mazanec DJ, et al. Acute low back pain and radiculopathy: MR imaging findings and their prognostic role and effect on outcome. Radiology. 2005;237(2):597-604.

31. Gilbert FJ, Grant AM, Gillan MGC, Vale LD, Campbell MK, Scott NW, et al. Low back pain: influence of early MR imaging or CT on treatment and outcome-multicenter randomized trial. Radiology. 2004;231(2):34351.
32. Shreibati JB, Baker LC. The relationship between low back magnetic resonance imaging, surgery, and spending: impact of physician selfreferral status. Health Serv Res. 2011;46(5):1362-81.

33. Webster BS, Choi Y, Bauer AZ, Cifuentes M, Pransky G. The cascade of medical services and associated longitudinal costs due to nonadherent magnetic resonance imaging for low back pain. Spine. 2014;39(17):143340 .

Publisher's Note Springer Nature remains neutral with regard to jurisdictional claims in published maps and institutional affiliations. 